\title{
Depression, subjective cognitive decline, and the risk of neurocognitive disorders
}

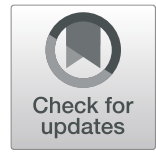

Tau Ming Liew ${ }^{1,2}$ D

\begin{abstract}
Background: Depression and subjective cognitive decline (SCD) both predict neurocognitive disorders (NCD). However, the two correlate strongly with each other. It remains uncertain whether they reflect independent neurobiological underpinnings which deserve separate attention. This study evaluated the independent risks of NCD associated with depression and SCD.

Methods: This cohort study included 13,462 participants who were $\geq 50$ years and had normal cognition at baseline. The participants were evaluated for depression and SCD and followed up almost annually for incident mild cognitive impairment or dementia (MCl/dementia) (median follow-up $=4.4$ years). Depression and SCD were included in Cox-regression to investigate their independent risks of $\mathrm{MCl} /$ dementia.

Results: At baseline, 1307 participants (9.7\%) had depression and 3582 (26.6\%) had SCD. During follow-up, 1490 (11.1\%) developed MCl/dementia. Depression and SCD demonstrated independent risks of MCl/dementia (HR 1.4 and 2.0 respectively). The risk was highest when depression and SCD co-occur (HR 2.8), with half of the participants in this group developing $\mathrm{MCl} /$ dementia within 7.2 years of follow-up (compared to 12.2 years in participants without depression or SCD).

Conclusions: The findings may change the clinical approach in managing SCD in depression, suggesting the need for greater emphasis on detecting prodromal NCD. They may also have implications to our understanding of NCD, suggesting the need for further research to delineate the commonalities and distinctions in the neurobiological pathways of depression and SCD.
\end{abstract}

Keywords: Subjective cognitive complaints, Geriatric depression scale, Mild cognitive impairment, Dementia, Cohort study, Cox regression

\section{Introduction}

Subjective cognitive decline (SCD) refers to a person's subjective experience of worsening in cognition (typically in the memory domain), in the absence of objective cognitive deficits [1]. It is increasingly common with advancing age [2], with large community-based studies in the literature pointing to a prevalence of $50-60 \%$ among older persons $[3,4]$. In recent years, SCD has gained attention as a plausible predictor for incident neurocognitive disorders (NCD) and has been suggested to be useful in the diagnosis of prodromal NCD $[1,5]$. In the 2018 NIA-AA research framework for Alzheimer's

\footnotetext{
Correspondence: tau_ming_liew@imh.com.sg

${ }^{1}$ Department of Geriatric Psychiatry, Institute of Mental Health, 10 Buangkok View, Singapore 539747, Singapore

${ }^{2}$ Saw Swee Hock School of Public Health, National University of Singapore, Singapore, Singapore
}

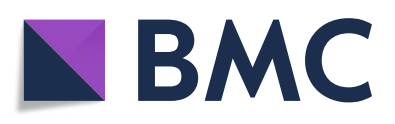

(c) The Author(s). 2019 Open Access This article is distributed under the terms of the Creative Commons Attribution 4.0 International License (http://creativecommons.org/licenses/by/4.0/), which permits unrestricted use, distribution, and

reproduction in any medium, provided you give appropriate credit to the original author(s) and the source, provide a link to the Creative Commons license, and indicate if changes were made. The Creative Commons Public Domain Dedication waiver (http://creativecommons.org/publicdomain/zero/1.0/) applies to the data made available in this article, unless otherwise stated. phase in the continuum from normal cognition to early NCD.

Notwithstanding the evidence supporting the usefulness of SCD, the literature has not been conclusive on the validity of SCD in identifying prodromal NCD [7, 8]-especially in the context of psychiatric disorders such as depression [1, 5]-and was specifically highlighted in the recently published research framework on SCD $[1,5]$. SCD can often co-occur with depression among older persons $[1,5,7,8]$ and is not uncommonly the chief complaint of older persons with depression [8]. Considering such strong correlation between SCD and depression $[1,5,7,8]$, the literature remains uncertain whether SCD truly represents a separate disease process from that of depression, or is merely an alternate 
measure of a common neurobiology which is also related to depression $[7,8]$.

Using a large sample, this study sought to provide the confirmatory evidence on whether SCD truly has an independent effect-separate from that of depression-on the risk of mild cognitive impairment (MCI) and dementia, and hence reflects an independent neurobiological underpinning that deserves separate attention from that of depression.

\section{Methods}

\section{Study population}

This cohort study is based on the National Alzheimer's Coordinating Center (NACC) [9] database, involving participants who were recruited from the Alzheimer's Disease Centers across the USA and followed up almost annually for incident mild cognitive impairment (MCI) and dementia. It included participants who fulfilled the following criteria: (1) recruited between September 2005 and May 2018, (2) aged $\geq 50$ years, (3) diagnosed as having normal cognition at baseline (that is, participants had received clinical evaluations at baseline and found not to have MCI or dementia), and (4) completed the Geriatric Depression Scale (GDS) and a question on SCD at baseline. Research using the NACC database was approved by the University of Washington InstitutionalReview-Board. Written informed consents were obtained from all the participants.

\section{Measures}

SCD was evaluated with a single yes/no question based on whether the participant perceived "a decline in memory relative to previously attained abilities". The focus on the memory domain is not inconsistent with the current evidence in the literature, particularly in the recently proposed SCD framework [1], where memory concerns have been suggested to demonstrate better likelihood (than other non-memory concerns) in detecting prodromal NCD. GDS [10] assesses the level of depressive symptoms over the past week using 15 yes/no questions. The responses are summed to produce a total score, with higher scores indicating higher levels of depressive symptoms. The original GDS includes, among the 15 items, an item that seems to also capture the construct of SCD (item 10: Do you feel you have more problems with memory than most?). To avoid confounding the relationship between depression and SCD, this item 10 was excluded from the total score of GDS, resulting in a total maximum score of 14 (instead of the original total score of 15). In this study, GDS $\geq 4$ was used to identify those with depression. This is not inconsistent with the findings from a recent diagnostic meta-analysis [11], where GDS $\geq 4$ was identified as the optimal cut-off score to detect major depression-it has the highest
Diagnostic Odds Ratio across the various cut-off scores, as well as demonstrated a good balance between sensitivity and specificity ( $88 \%$ and $86 \%$, respectively). Notwithstanding this, alternative cut-off scores (GDS $>0$, GDS $\geq 5$, and GDS $\geq 6$ ) were also tested in the subsequent sensitivity analyses to examine the robustness of the results to the choice of cut-off score. The Mini-Mental-State-Examination (MMSE) [12] was measured in this study and included in the analyses as one of the potential confounders. MMSE is a widely used cognitive assessment tool. It consists of 11 items across cognitive domains such as orientation, memory, concentration, language, and constructional praxis.

The diagnoses of MCI and dementia were made based on all available information from standardized assessments [9], with $74.1 \%$ made via consensus conference and the remainder made by single clinicians. MCI was diagnosed using the modified Petersen criteria [13], while dementia was diagnosed using either the McKhann (1984) criteria [14] or the McKhann (2011) criteria [15].

\section{Statistical analyses}

Cox proportional-hazard regression was conducted to evaluate the risk of $\mathrm{MCI}$ and dementia related to depression and subjective cognitive decline, with timeto-event defined as the duration from study recruitment to the diagnosis of either MCI or dementia. In the Cox regression, the baseline presence of depression (GDS $\geq 4$ ) and SCD was concurrently included to evaluate the unique risks that were attributable to each of them (after adjusting for the effects of each other). The cox regression adjusted for potential confounders that are known to predict neurocognitive disorders [16], including the baseline covariates of age, sex, ethnicity, years of education, family history of dementia, current smoking, hypertension, hyperlipidemia, diabetes mellitus, and MMSE.

The proportional hazard assumption of Cox regression was tested statistically based on whether the Schoenfeld residuals were associated with time-variables that violated the proportional hazard assumption $(P<0.05)$ were included in the Cox regression as stratified variable. Inverse probability weighting (IPW) [17] was used in Cox regression to account for participants who did not have follow-up data. IPW is a well-accepted strategy which gives more weight to participants who resemble those who did not have follow-up data and ensures that the results are less biased towards participants who provided follow-up data [17, 18]. As such, this method minimizes any potential bias in the results due to differential risks between those with and without follow-up data. Further details on IPW are available in Additional file 1. 
Six sensitivity analyses were conducted to evaluate the consistency of the results when some parts of the main analysis were modified. They included:

(1) Using the presence of depressive symptoms (GDS > 0 ), instead of the presence of depression (which was defined as $\mathrm{GDS} \geq 4$ )

(2) Using a more stringent cut-off score of GDS $\geq 5$ to define depression (instead of GDS $\geq 4$ )

(3) Using an even more stringent cut-off score of GDS $\geq 6$ to define depression (instead of GDS $\geq 4$ )

(4) Adjusting additionally for the covariate of antidepressant use at baseline (of note, $18.2 \%$ of the participants reported the use of antidepressant at baseline)

(5) Using dementia as the primary endpoint (instead of the composite endpoint of mild cognitive impairment or dementia)
(6) Analyzing only the complete cases with available follow-up data $(n=10,219)$

Additionally, a stratified analysis was conducted to evaluate the risks of MCI and dementia across different combinations of presentation, as classified by the presence of depression or SCD at baseline. All statistical analyses were conducted in Stata (version 14).

\section{Results}

A total of 13,462 participants were included in this study, of which $24.1 \%$ only had baseline data and did not contribute to follow-up data, while the rest of the participants had a median duration of follow-up of 4.4 years (interquartile range, IQR 2.2-7.4 years). The flow diagram related to participant selection is shown in Fig. 1, while the participant characteristics (as well as the comparison between participants with and without follow-up

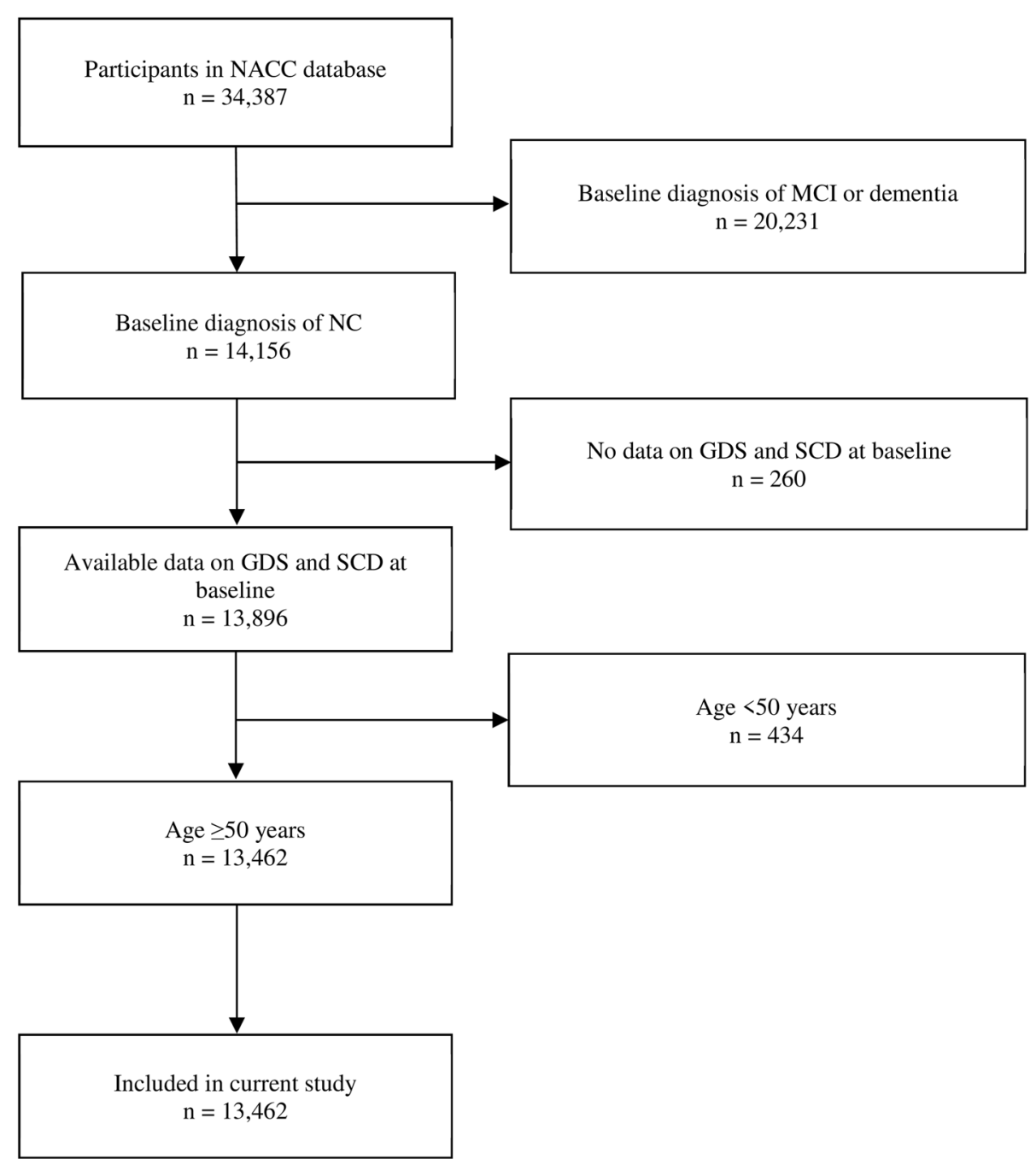

Fig. 1 Participant enrolment and exclusion details. NACC, National Alzheimer's Coordinating Center; MCl, mild cognitive impairment; NC, normal cognition; GDS, geriatric depression scale; SCD, subjective cognitive decline 
Table 1 Demographic information of the study participants at baseline $(n=13,462)$ and comparison between those with and without longitudinal follow-up data

\begin{tabular}{|c|c|c|c|c|}
\hline Variable & $\begin{array}{l}\text { Overall sample }(n= \\
13,462)\end{array}$ & $\begin{array}{l}\text { Participants with follow-up data } \\
(n=10,219)\end{array}$ & $\begin{array}{l}\text { Participants without follow-up data } \\
(n=3243)\end{array}$ & $\begin{array}{l}P \\
\text { value }^{\mathrm{a}} \\
\end{array}$ \\
\hline Age, median (IQR) & $71(65-78)$ & $72(66-78)$ & $70(64-76)$ & $<0.001$ \\
\hline Years of education, median (IQR) & $16(14-18)$ & $16(14-18)$ & $16(14-18)$ & 0.353 \\
\hline Male sex, $n(\%)$ & $4629(34.4)$ & $3541(34.7)$ & $1088(33.6)$ & 0.250 \\
\hline Ethnicity, $n$ (\%) & & & & $<0.001$ \\
\hline White & 10,633 (79.0) & 8209 (80.3) & $2424(74.8)$ & \\
\hline African American & $1924(14.3)$ & $1397(13.7)$ & $527(16.3)$ & \\
\hline Others/unknown & $905(6.7)$ & $613(6.0)$ & $292(9.0)$ & \\
\hline Marital status, $n(\%)$ & & & & $<0.001$ \\
\hline Married & $7988(59.3)$ & 6095 (59.6) & $1893(58.4)$ & \\
\hline Widowed & $2566(19.1)$ & $2047(20.0)$ & $519(16.0)$ & \\
\hline Divorced/separated & $1964(14.6)$ & $1382(13.5)$ & $582(18.0)$ & \\
\hline Single & $829(6.2)$ & $611(6.0)$ & $218(6.7)$ & \\
\hline Other/unknown & $115(0.9)$ & $84(0.8)$ & $31(1.0)$ & \\
\hline Living arrangement, $n$ (\%) & & & & $<0.001$ \\
\hline Lives alone & $4445(33.0)$ & 3409 (33.4) & $1036(32.0)$ & \\
\hline Lives with spouse & $7817(58.1)$ & $5970(58.4)$ & $1847(57.0)$ & \\
\hline Lives with relative or friend & $933(6.9)$ & $675(6.6)$ & $258(8.0)$ & \\
\hline Lives with group/other & $267(2.0)$ & $165(1.6)$ & $102(3.2)$ & \\
\hline Type of residence, $n$ (\%) & & & & $<0.001$ \\
\hline Private residence & $12,207(90.7)$ & 9146 (89.5) & $3061(94.4)$ & \\
\hline Retirement community & $950(7.1)$ & $821(8.0)$ & $129(4.0)$ & \\
\hline Assisted living/nursing home/other & $305(2.3)$ & $252(2.5)$ & $53(1.6)$ & \\
\hline Primary reason of participation, $n$ (\%) & & & & $<0.001$ \\
\hline To participate in research & $11,848(88.0)$ & $9088(88.9)$ & $2760(85.1)$ & \\
\hline For clinical evaluation & $1240(9.2)$ & $927(9.1)$ & $313(9.7)$ & \\
\hline $\begin{array}{l}\text { For clinical evaluation and participate } \\
\text { in research }\end{array}$ & $359(2.7)$ & $192(1.9)$ & $167(5.2)$ & \\
\hline Unknown & $15(0.1)$ & $12(0.1)$ & $3(0.1)$ & \\
\hline Primary source of referral, $n(\%)$ & & & & $<0.001$ \\
\hline Self/relative/friend & $5685(42.2)$ & $4217(41.3)$ & $1468(45.3)$ & \\
\hline Healthcare providers & $2441(18.1)$ & $1634(16.0)$ & 807 (24.9) & \\
\hline Other & $4924(36.6)$ & $4016(39.3)$ & $908(28.0)$ & \\
\hline Unknown & $412(3.1)$ & $352(3.4)$ & $60(1.9)$ & \\
\hline Family history of dementia, $n(\%)$ & $7274(54.0)$ & $5700(55.8)$ & $1574(48.5)$ & $<0.001$ \\
\hline Current smoker, $n$ (\%) & & & & $<0.001$ \\
\hline Yes & $664(4.9)$ & $507(5.0)$ & $157(4.8)$ & \\
\hline No & $12,774(94.9)$ & $9703(95.0)$ & 3071 (94.7) & \\
\hline Missing data & $24(0.2)$ & $9(0.1)$ & $15(0.5)$ & \\
\hline Diabetes mellitus, $n$ (\%) & & & & 0.008 \\
\hline Yes & 1592 (11.8) & $1160(11.4)$ & $432(13.3)$ & \\
\hline No & $11,832(87.9)$ & $9028(88.4)$ & 2804 (86.5) & \\
\hline Missing data & $38(0.3)$ & $31(0.3)$ & $7(0.2)$ & \\
\hline Hypertension, n (\%) & & & & 0.225 \\
\hline
\end{tabular}


Table 1 Demographic information of the study participants at baseline $(n=13,462)$ and comparison between those with and without longitudinal follow-up data (Continued)

\begin{tabular}{|c|c|c|c|c|}
\hline Variable & $\begin{array}{l}\text { Overall sample }(n= \\
13,462)\end{array}$ & $\begin{array}{l}\text { Participants with follow-up data } \\
(n=10,219)\end{array}$ & $\begin{array}{l}\text { Participants without follow-up data } \\
(n=3243)\end{array}$ & $\begin{array}{l}P \\
\text { value }^{\mathrm{a}}\end{array}$ \\
\hline Yes & $6628(49.2)$ & $5074(49.7)$ & $1554(47.9)$ & \\
\hline No & $6795(50.5)$ & $5116(50.1)$ & $1679(51.8)$ & \\
\hline Missing data & $39(0.3)$ & $29(0.3)$ & $10(0.3)$ & \\
\hline Hyperlipidemia, $n(\%)$ & & & & 0.452 \\
\hline Yes & $6609(49.1)$ & $5038(49.3)$ & $1571(48.4)$ & \\
\hline No & $6693(49.7)$ & $5065(49.6)$ & $1628(50.2)$ & \\
\hline Missing data & $160(1.2)$ & $116(1.1)$ & $44(1.4)$ & \\
\hline MMSE score, median (IQR) & $29(28-30)$ & $29(28-30)$ & $29(28-30)$ & 0.607 \\
\hline GDS score, median (IQR) & $1(0-2)$ & $1(0-2)$ & $1(0-2)$ & $<0.001$ \\
\hline Presence of depression (GDS $\geq 4), n(\%)$ & $1471(10.9)$ & $993(9.7)$ & $478(14.7)$ & $<0.001$ \\
\hline Presence of SCD, $n(\%)$ & $3582(26.6)$ & $2605(25.5)$ & $977(30.1)$ & $<0.001$ \\
\hline
\end{tabular}

IQR interquartile range, MMSE Mini-Mental State Examination, GDS geriatric depression scale, SCD subjective cognitive decline

${ }^{\text {a } T e s t ~ o f ~ d i f f e r e n c e ~ b e t w e e n ~ p a r t i c i p a n t s ~ w i t h ~ a n d ~ w i t h o u t ~ l o n g i t u d i n a l ~ f o l l o w-u p ~ d a t a: ~ c h i-s q u a r e ~ t e s t ~ f o r ~ c a t e g o r i c a l ~ v a r i a b l e s ~ a n d ~ M a n n-W h i t n e y ~} \mathrm{U}$ test for continuous variables. Italicized $P$ values are $\leq 0.05$

data) are presented in Table 1 . The participants had a median age of 71 (IQR 65-78) and a median MMSE score of 29 (IQR 28-30). At baseline, 1307 participants $(9.7 \%)$ reported the presence of depression (GDS $\geq 4$ ), while 3582 (26.6\%) reported the presence of SCD. During follow-up, 1490 (11.1\%) converted to MCI, while 695 (5.2\%) converted to dementia (with 533 being Alzheimer's dementia, 62 vascular dementia, 34 dementia with Lewy Bodies, 13 frontotemporal lobar degeneration, and 53 due to other or unknown etiology).

In Cox regression, both depression and SCD demonstrated independent risks of MCI and dementia (hazard ratio, HR of 1.4 for depression and 2.0 for SCD) (Table 2). The findings remained consistent in the six sensitivity analyses, with minimal change to the risk estimates of depression and SCD, and are further presented in Additional file 2.

Table 2 The risk of mild cognitive impairment and dementia based on the presence of depression and subjective cognitive decline $(n=13,462)$

\begin{tabular}{|c|c|c|c|c|}
\hline \multirow[t]{2}{*}{ Adjustment model } & \multicolumn{2}{|l|}{ Depression } & \multicolumn{2}{|l|}{ SCD } \\
\hline & $\operatorname{HR}(95 \% \mathrm{Cl})^{\mathrm{a}}$ & $P$ value & $\operatorname{HR}(95 \% \mathrm{Cl})^{\mathrm{a}}$ & $P$ value \\
\hline Model 1 (unadjusted) ${ }^{a}$ & $1.4(1.2-1.6)$ & $<0.001$ & $2.0(1.8-2.2)$ & $<0.001$ \\
\hline Model $2^{b}$ & $1.5(1.3-1.7)$ & $<0.001$ & $2.1(1.9-2.3)$ & $<0.001$ \\
\hline Model $3^{c}$ & $1.4(1.2-1.6)$ & $<0.001$ & $2.1(1.9-2.3)$ & $<0.001$ \\
\hline Model 4 (final) $^{d}$ & $1.4(1.2-1.6)$ & $<0.001$ & $2.0(1.9-2.2)$ & $<0.001$ \\
\hline \multicolumn{5}{|c|}{ 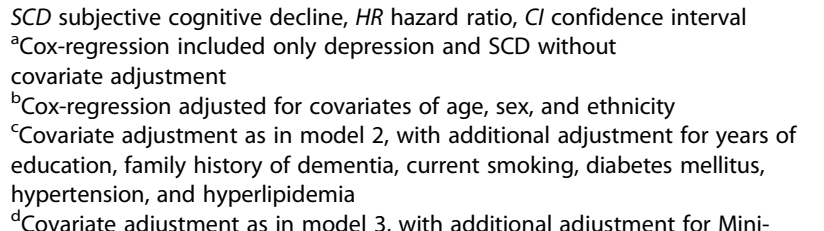 } \\
\hline
\end{tabular}

The risks of MCI and dementia were then stratified by the presence of depression or SCD at baseline. As shown in Table 3, the HR of MCI and dementia increased incrementally from depression only (HR 1.4), to SCD only (HR 2.0), and to both depression and SCD (HR 2.8). Notably, there was no overlap in the $95 \%$ CI of the different combinations of presentation, reflecting the significance of the respective increment in HR. Among individuals without depression or SCD, half of them developed MCI or dementia within 12.2 years of follow-up. This duration shortened to 7.2 years in the presence of both depression and SCD. The Kaplan-Meier curves for the different combinations of presentation are presented in Fig. 2.

\section{Discussion}

This study utilized a large sample of cognitively normal older persons and a longitudinal study design, to investigate the relationships among depression, SCD, and incident NCD. Both depression and SCD were independently associated with the risk of MCI and dementia, with HR of 1.4 and 2.0, respectively. The results were robust to several sensitivity analyses. Co-occurring depression and SCD had the highest risk of developing NCD (HR 2.8), with half of the participants in this group developing NCD within 7.2 years of follow-up (compared to 12.2 years in participants without depression or SCD).

The findings may have implications to health services which are involved in the care of older persons. SCD often co-occurs with depression $[1,5,7,8]$ and is not uncommonly the primary presentation of older persons with depression to many health services [8]. Until recently, the evidence has been uncertain on the unique role of SCD on NCD, in the context of depression $[1,5$, 
Table 3 Risk of mild cognitive impairment and dementia across the different combinations of presentation $(n=13,462)$

\begin{tabular}{llll}
\hline Different combinations of presentation & $\mathrm{HR}(95 \% \mathrm{Cl})^{\mathrm{a}}$ & $P$ value & Median time to $\mathrm{MCl}$ and dementia, year $(95 \% \mathrm{Cl})^{\mathrm{b}}$ \\
\hline No depression or SCD & $1.0($ Ref $)$ & Ref & $12.2(12.1-12.3)$ \\
Depression only & $1.4(1.1-1.7)$ & 0.004 & $12.1(11.6-12.2)$ \\
SCD only & $2.0(1.8-2.2)$ & $<0.001$ & $9.8(9.1-10.2)$ \\
Both depression and SCD & $2.8(2.4-3.4)$ & $<0.001$ & $7.2(5.2-9.1)$ \\
\hline
\end{tabular}

$H R$ hazard ratio, $\mathrm{Cl}$ confidence interval, $\mathrm{MCl}$ mild cognitive impairment, $S C D$ subjective cognitive decline, Ref reference group

${ }^{a}$ Model adjusted for baseline variables of age, sex, ethnicity, years of education, family history of dementia, current smoking, diabetes mellitus, hypertension, hyperlipidemia, and Mini-Mental State Examination score

${ }^{\mathrm{b}}$ The $95 \% \mathrm{Cl}$ was computed with 1000 bootstrap sampling

7, 8]. This has translated into the prevailing practice where SCD in depression is viewed primarily as a moodrelated symptom [7], with minimal emphasis to followup on the patients' cognitive function or monitor for the onset of NCD (apart from the initial cognitive screening to rule out NCD as the primary diagnosis). The findings from the current study allow us to draw a more definite conclusion on the independent role of SCD in depression and may potentially change our approach in the management of SCD among older persons with depression. In older patients with depression, the presence of SCD can indicate a very high risk of NCD. While the focus on managing depression remains pertinent to improve the quality of life of the patients, there may be an equally relevant need to closely monitor these patients for incident NCD. Potentially, the newer biomarkers of NCD (such as those related to amyloid protein, tau protein, and neuronal injury) [6] may be useful in these patients to identify those at very early stages of NCD for timely preventive interventions, especially when the biomarkers become more accessible to general clinicians in the foreseeable future. In future preventive trials, the identification of co-occurring depressive symptoms and SCD may also be a useful recruitment strategy to select cognitively normal individuals who are at high risk of developing NCD [19], given that these individuals are more likely to develop NCD within a shorter time frame, and hence, the efficiency of clinical trials may be improved by reducing the duration of follow-up to the outcome of interest.

The findings may potentially also have implications to our understanding of NCD. Depression and SCD have been shown to correlate strongly with each other in prior studies $[1,5,7,8]$ and, hence traditionally, have often been understood as arising from the same construct along the continuum of depressive symptoms [7, 8]. The findings from this study suggest that depression and SCD are plausibly two distinct constructs that may independently lead to $\mathrm{NCD}$, which then raises further question, on whether the two may also have distinct neurobiological pathways that lead to NCD. Prior studies have already implicated different sets of neurobiology for

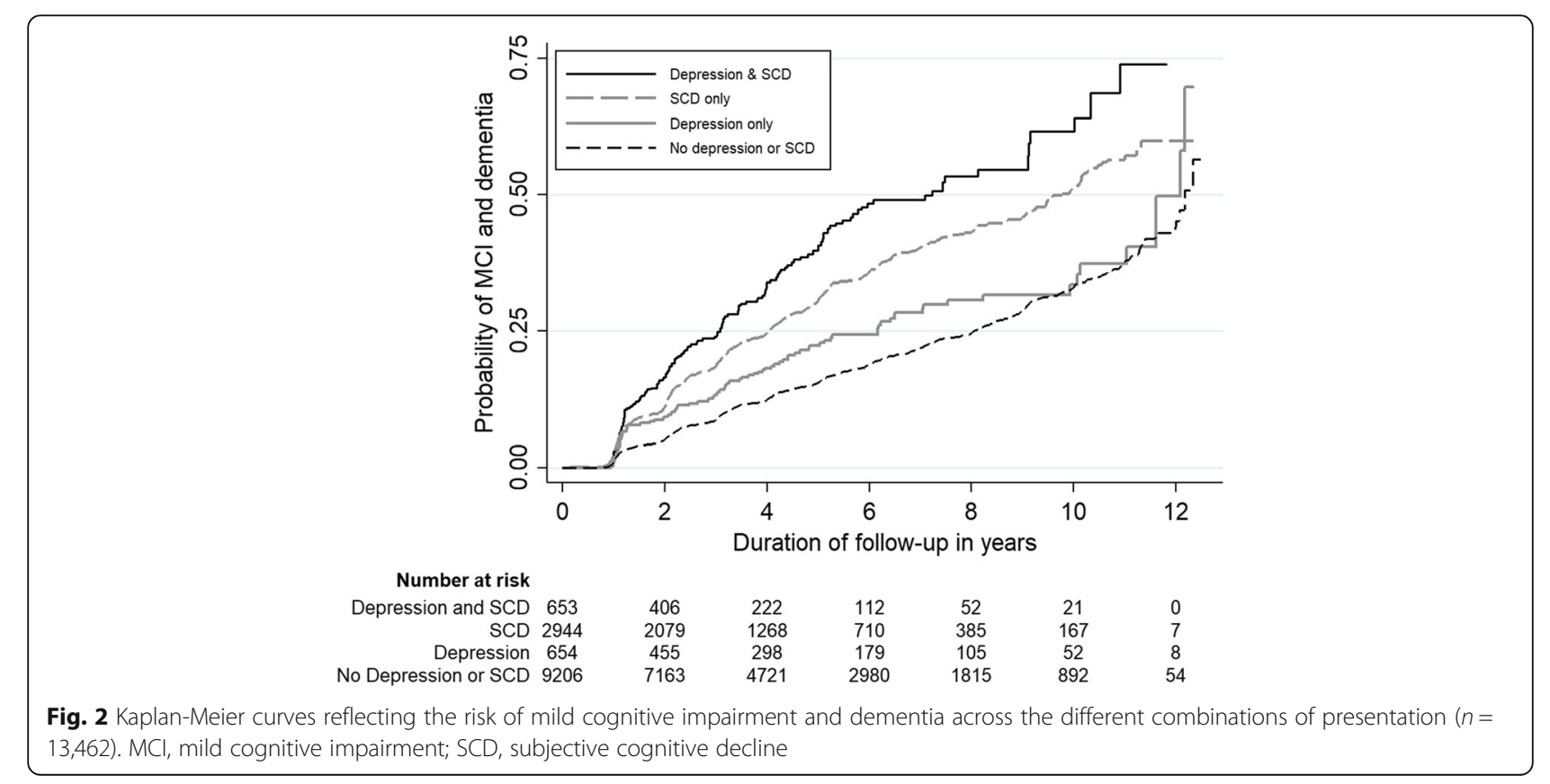


depression and SCD. For example, in studies of neurotransmitters, the monoaminergic system in the brain stem have been associated with depression [20], while the cholinergic system in the basal forebrain has been linked to SCD [21]. In studies of neuroanatomical regions, changes in entorhinal, anterior cingulate, and left middle frontal cortices have been associated with depression in patients with prodromal NCD [22], while white matter lesions, smaller left hippocampal volumes, and temporal lobe atrophy have been linked to SCD [23]. However, it remains uncertain whether the reported neurobiological evidences are still shared between depression and SCD, which indicates that depression and SCD are merely two presentations of a common NCD pathology, or whether depression and SCD may involve two distinct neurobiological pathways that converge to lead to NCD. Further research is needed to clarify on this uncertainty-if the latter hypothesis may plausibly be true, the delineation of differing pathways may potentially improve our understanding on the pathogenesis of NCD as well as identify new drug targets which may inform future development of disease-modifying drugs for NCD.

Several limitations should be considered. First, the participants in the study involved those who volunteered at the Alzheimer's Disease Centers. They may be more representative of patients who voluntarily present to healthcare settings than those in the community. Second, depression in this study was defined based on established cut-off scores on GDS. Although GDS does not produce a definitive diagnosis of clinical depression, this depression scale has been shown in a recent diagnostic meta-analysis [11] to have excellent sensitivity and specificity, especially at its optimal cut-off score of GDS $\geq 4$, in detecting major depression. Moreover, the results remained consistent in the sensitivity analyses, even with alternative cut-off scores of GDS (that is, GDS $\geq 5$ and GDS $\geq 6$ ), which lend some credence to the validity of the findings. Third, the SCD measure in this study was based on a single question and focused on the memory domain. While this may not be an uncommon practice in the current literature on SCD [24, 25], such SCD measure may not have captured the full range of memory concerns or other non-memory domains. Fourth, the diagnoses of $\mathrm{MCI}$ and dementia were made by single clinicians in $25.9 \%$ of the participants. They may not necessarily be as accurate as those made via consensus conference.

\section{Conclusion}

Depression and SCD demonstrated independent risks on the subsequent development of NCD, with the risk being highest when both co-occur. The findings may change the clinical approach in the management of SCD in depression, suggesting the need for greater emphasis on detecting prodromal NCD when older patients with depression present with SCD. They may also have implications to our understanding of NCD, suggesting the need for further research to delineate the commonalities and distinctions in the neurobiological pathways of depression and SCD.

\section{Additional files}

Additional file 1: Details on the conduct of inverse probability weighting to account for those who did not have follow-up data after the first visit. (DOCX $74 \mathrm{~kb}$ )

Additional file 2 Results from the six sensitivity analyses to evaluate the robustness of the main findings. (DOCX $73 \mathrm{~kb}$ )

\section{Abbreviations}

AP: Attributable proportion; Cl: Confidence interval; GDS: Geriatric Depression Scale; HR: Hazard ratio; IPW: Inverse probability weighting; IQR: Inter-quartile range; $\mathrm{MCl}$ : Mild cognitive impairment; MMSE: Mini-Mental State Examination; NACC: National Alzheimer's Coordinating Center; NCD: Neurocognitive disorders; SCD: Subjective cognitive decline

\section{Acknowledgements}

The NACC database is funded by NIA/NIH Grant U01 AG016976. NACC data are contributed by the NIA-funded ADCs: P30 AG019610 (PI Eric Reiman, MD), P30 AG013846 (PI Neil Kowall, MD), P50 AG008702 (PI Scott Small, MD), P50 AG025688 (PI Allan Levey, MD, PhD), P50 AG047266 (PI Todd Golde, MD, PhD), P30 AG010133 (PI Andrew Saykin, PsyD), P50 AG005146 (PI Marilyn Albert, PhD), P50 AG005134 (PI Bradley Hyman, MD, PhD), P50 AG016574 (PI Ronald Petersen, MD, PhD), P50 AG005138 (PI Mary Sano, PhD), P30 AG008051 (PI Thomas Wisniewski, MD), P30 AG013854 (PI M. Marsel Mesulam, MD), P30 AG008017 (PI Jeffrey Kaye, MD), P30 AG010161 (PI David Bennett, MD), P50 AG047366 (PI Victor Henderson, MD, MS), P30 AG010129 (PI Charles DeCarli, MD), P50 AG016573 (PI Frank LaFerla, PhD), P50 AG005131 (PI James Brewer, MD, PhD), P50 AG023501 (PI Bruce Miller, MD), P30 AG035982 (PI Russell Swerdlow, MD), P30 AG028383 (PI Linda Van Eldik, PhD), P30 AG053760 (PI Henry Paulson, MD, PhD), P30 AG010124 (PI John Trojanowski, MD, PhD), P50 AG005133 (PI Oscar Lopez, MD), P50 AG005142 (PI Helena Chui, MD), P30 AG012300 (PI Roger Rosenberg, MD), P30 AG049638 (PI Suzanne Craft, PhD), P50 AG005136 (PI Thomas Grabowski, MD), P50 AG033514 (PI Sanjay Asthana, MD, FRCP), P50 AG005681 (PI John Morris, MD), and P50 AG047270 (PI Stephen Strittmatter, MD, PhD).

\section{Author's contributions}

The author read and approved the final manuscript.

\section{Funding}

TML is supported by research grants under the National Medical Research Council of Singapore (grant number NMRC/Fellowship/0030/2016 and NMRC/CSSSP/0014/2017). The funding sources had no involvement in any part of the project.

\section{Availability of data and materials}

The data were obtained from the National Alzheimer's Coordinating Center (NACC). For further information on access to the database, please contact NACC (contact details can be found at https://www.alz.washington.edu/WEB/ researcher_home.html).

Ethics approval and consent to participate

Research using the NACC database was approved by the University of Washington Institutional-Review-Board. Written informed consents were obtained from all the participants.

Consent for publication

Not applicable. 


\section{Competing interests}

The author declares no competing interests.

Received: 13 April 2019 Accepted: 30 July 2019

Published online: 09 August 2019

\section{References}

1. Jessen $F$, Amariglio RE, van Boxtel M, Breteler M, Ceccaldi M, Chetelat $G$, Dubois B, Dufouil C, Ellis KA, van der Flier WM, et al. A conceptual framework for research on subjective cognitive decline in preclinical Alzheimer's disease. Alzheimers Dement. 2014:10(6):844-52.

2. Mitchell AJ. Is it time to separate subjective cognitive complaints from the diagnosis of mild cognitive impairment? Age Ageing. 2008;37(5):497-9.

3. Singh-Manoux A, Dugravot A, Ankri J, Nabi H, Berr C, Goldberg M, Zins M, Kivimaki M, Elbaz A. Subjective cognitive complaints and mortality: does the type of complaint matter? J Psychiatr Res. 2014;48(1):73-8.

4. Holmen J, Langballe EM, Midthjell K, Holmen TL, Fikseaunet A, Saltvedt I, Tambs K. Gender differences in subjective memory impairment in a general population: the HUNT study, Norway. BMC Psychol. 2013;1(1):19.

5. Molinuevo JL, Rabin LA, Amariglio R, Buckley R, Dubois B, Ellis KA, Ewers M, Hampel H, Kloppel S, Rami L, et al. Implementation of subjective cognitive decline criteria in research studies. Alzheimers Dement. 2017;13(3):296-311.

6. Jack CR Jr, Bennett DA, Blennow K, Carrillo MC, Dunn B, Haeberlein SB, Holtzman DM, Jagust W, Jessen F, Karlawish J, et al. NIA-AA Research Framework: toward a biological definition of Alzheimer's disease. Alzheimers Dement. 2018;14(4):535-62.

7. Burmester B, Leathem J, Merrick P. Subjective cognitive complaints and objective cognitive function in aging: a systematic review and meta-analysis of recent cross-sectional findings. Neuropsychol Rev. 2016;26(4):376-93.

8. Reid LM, Maclullich AM. Subjective memory complaints and cognitive impairment in older people. Dement Geriatr Cogn Disord. 2006;22(5-6):47185.

9. Beekly DL, Ramos EM, van Belle G, Deitrich W, Clark AD, Jacka ME, Kukull WA. The National Alzheimer's Coordinating Center (NACC) Database: an Alzheimer disease database. Alzheimer Dis Assoc Disord. 2004;18(4):270-7.

10. Sheikh Jl, Yesavage JA. Geriatric depression scale (GDS): recent evidence and development of a shorter version. Clin Gerontol. 1986;5(1-2):165-73.

11. Pocklington C, Gilbody S, Manea L, McMillan D. The diagnostic accuracy of brief versions of the geriatric depression scale: a systematic review and meta-analysis. Int J Geriatr Psychiatry. 2016;31 (8):837-57.

12. Folstein MF, Folstein SE, McHugh PR. "Mini-mental state". A practical method for grading the cognitive state of patients for the clinician. J Psychiatr Res. 1975;12(3):189-98.

13. Petersen RC, Morris JC. Mild cognitive impairment as a clinical entity and treatment target. Arch Neurol. 2005;62(7):1160-3 discussion 1167.

14. McKhann G, Drachman D, Folstein M, Katzman R, Price D, Stadlan EM: Clinical diagnosis of Alzheimer's disease. Report of the NINCDS-ADRDA Work Group* under the auspices of Department of Health and Human Services Task Force on Alzheimer's Disease 1984, 34(7):939-939.

15. McKhann GM, Knopman DS, Chertkow H, Hyman BT, Jack CR, Kawas CH, Klunk WE, Koroshetz WJ, Manly JJ, Mayeux R, et al. The diagnosis of dementia due to Alzheimer's disease: recommendations from the National Institute on Aging-Alzheimer's Association workgroups on diagnostic guidelines for Alzheimer's disease. Alzheimers Dement. 2011;7(3):263-9.

16. Baumgart M, Snyder HM, Carrillo MC, Fazio S, Kim H, Johns H. Summary of the evidence on modifiable risk factors for cognitive decline and dementia: a population-based perspective. Alzheimers Dement. 2015;11(6):718-26.

17. Seaman $S R$, White IR. Review of inverse probability weighting for dealing with missing data. Stat Methods Med Res. 2013;22(3):278-95.

18. Liew TM. Symptom clusters of neuropsychiatric symptoms in mild cognitive impairment and their comparative risks of dementia: a cohort study of 8530 older persons. J Am Med Dir Assoc. 2019;20(8):1054.e1-9.

19. Donovan NJ, Amariglio RE, Zoller AS, Rudel RK, Gomez-Isla T, Blacker D, Hyman BT, Locascio JJ, Johnson KA, Sperling RA, et al. Subjective cognitive concerns and neuropsychiatric predictors of progression to the early clinical stages of Alzheimer disease. Am J Geriatr Psychiatry. 2014;22(12):1642-51.

20. Geda YE, Schneider LS, Gitlin LN, Miller DS, Smith GS, Bell J, Evans J, Lee M, Porsteinsson A, Lanctot KL, et al. Neuropsychiatric symptoms in Alzheimer's disease: past progress and anticipation of the future. Alzheimers Dement. 2013;9(5):602-8.
21. Scheef L, Grothe MJ, Koppara A, Daamen M, Boecker H, Biersack H, Schild $\mathrm{HH}$, Wagner M, Teipel S, Jessen F. Subregional volume reduction of the cholinergic forebrain in subjective cognitive decline (SCD). Neuroimage Clin. 2019:21:101612.

22. Rosenberg PB, Nowrangi MA, Lyketsos CG. Neuropsychiatric symptoms in Alzheimer's disease: what might be associated brain circuits? Mol Asp Med. 2015:43-44:25-37.

23. Mark RE, Sitskoorn MM. Are subjective cognitive complaints relevant in preclinical Alzheimer's disease? A review and guidelines for healthcare professionals. Rev Clin Gerontol. 2013;23(1):61-74.

24. Rabin LA, Smart CM, Crane PK, Amariglio RE, Berman LM, Boada M, Buckley RF, Chetelat G, Dubois B, Ellis KA, et al. Subjective cognitive decline in older adults: an overview of self-report measures used across 19 international research studies. J Alzheimers Dis. 2015;48(Suppl 1):S63-86.

25. Abdulrab K. Heun R. Subjective memory impairment. A review of its definitions indicates the need for a comprehensive set of standardised and validated criteria. Eur Psychiatry. 2008;23(5):321-30.

\section{Publisher's Note}

Springer Nature remains neutral with regard to jurisdictional claims in published maps and institutional affiliations.
Ready to submit your research? Choose BMC and benefit from:

- fast, convenient online submission

- thorough peer review by experienced researchers in your field

- rapid publication on acceptance

- support for research data, including large and complex data types

- gold Open Access which fosters wider collaboration and increased citations

- maximum visibility for your research: over $100 \mathrm{M}$ website views per year

At BMC, research is always in progress.

Learn more biomedcentral.com/submissions 